\title{
Clearance of Cell Remnants and Regeneration of Injured Muscle Depend on Soluble Pattern Recognition Receptor PTX3
}

\author{
Michela Vezzoli ${ }^{1 *}$ Clara Sciorati ${ }^{1 *}$ Lara Campana, ${ }^{1}$ Antonella Monno, ${ }^{1}$ Maria Giulia Doglio, ${ }^{1}$ \\ Elena Rigamonti, ${ }^{1}$ Gianfranca Corna ${ }^{1}$ Thierry Touvier, ${ }^{1}$ Alessandra Castiglioni, ${ }^{1}$ Annalisa Capobianco ${ }^{1}$ \\ Alberto Mantovani, ${ }^{2,3}$ Angelo A Manfredi, ${ }^{1,4}$ Cecilia Garlanda, ${ }^{2}$ and Patrizia Rovere-Querini ${ }^{1,4}$
}

${ }^{1}$ Division of Immunology, Transplantation, and Infectious Disease, San Raffaele Scientific Institute, Milan, Italy; ${ }^{2}$ Humanitas Clinical and Research Center, Rozzano, Milan, Italy; ${ }^{3}$ Humanitas University, Rozzano, Milan, Italy; and ${ }^{4}$ Vita-Salute San Raffaele University, School of Medicine, Milan, Italy

\begin{abstract}
The signals causing resolution of muscle inflammation are only partially characterized. The long pentraxin PTX3, which modulates leukocyte recruitment and activation, could contribute. We analyzed the expression of PTX3 after muscle injury and verified whether hematopoietic precursors are a source of the protein. The kinetics of regeneration and leukocyte infiltration and the accumulation of cell remnants and anti-histidyl-t-RNA synthetase autoantibodies were compared in wild-type and PTX3-deficient mice. PTX3 expression was upregulated $3 \mathrm{~d}$ to $5 \mathrm{~d}$ after injury and restricted to the extracellular matrix. Cellular debris and leukocytes persisted in the muscle of PTX3-deficient mice for a long time after wild-type animals had healed. PTX3-deficient macrophages expressed receptors involved in apoptotic cell clearance and engulfed dead cells in vitro. Accumulation of cell debris in a proinflammatory microenvironment was not sufficient to elicit autoantibodies. We concluded that PTX3 generated in response to muscle injury prompts clearance of debris and termination of the inflammatory response.
\end{abstract}

Online address: http://www.molmed.org

doi: $10.2119 / \mathrm{molmed} .2016 .00002$

\section{INTRODUCTION}

Pentraxins act as soluble pattern recognition molecules and are a component of the humoral arm of innate immunity (1,2). C-reactive protein and serum amyloid P-component are acute phase proteins released in response to inflammatory signals (1). PTX3 is the first identified member of the long pentraxin family; it contains a well-conserved pentraxin domain at the $\mathrm{C}$ terminus and a unique $\mathrm{N}$-terminal sequence. Macrophages, neutrophils and dendritic cells produce and release PTX3 in response to inflammatory signals (eg, IL-1 $\beta$ and TNF- $\alpha$ ) and Toll-like receptor activation $(1,3)$. PTX3 is also induced in fibroblasts and endothelial cells, smooth muscle cells, adipocytes and lung epithelial cells upon stimulation (1). The physiological functions attributed to pentraxins involve recognition and binding of different ligands: microbial moieties, complement components, apoptotic cell constituents, P-selectin and extracellular matrix proteins (4-8).

In vivo studies have demonstrated that expression of PTX3 is upregulated in

*MV and CS should be considered as co-first authors.

Address correspondence to Patrizia Rovere-Querini, San Raffaele Scientific Institute, via Olgettina 58, 20132 Milano, Italy. Phone: + 39 0226436768; Fax: + 39 0226434786; E-mail: rovere.patrizia@hsr.it Submitted January 2, 2016; Accepted for Publication September 29, 2016; Published Online (www.molmed.org) November 23, 2016.

Yทำ

Feinstein Institute for Medical Research Northwell Health" 
matrix that accumulates at the site of injury (18).

Clearance of debris is a critical step to allow effective reconstitution of injured tissues and induction of tolerance $(19,20)$. PTX3 in vitro modulates phagocytic clearance of postapoptotic debris $(3,16,21,22)$, a process that depends on PTX3's physical interaction with other humoral immunity molecules, in particular complement and ficolins (23). In Fas-deficient mice, which are characterized by lymphoaccumulation and display features of lupus-like autoimmunity, absence of PTX3 impairs the phagocytic uptake of apoptotic cells by peritoneal macrophages and aggravates spontaneous lung inflammation (24). Muscle stem cells have been shown to express autoantigens associated with idiopathic inflammatory myopathies (IIMs) $(25,26)$, and apoptotic myoblasts have been shown to effectively trigger autoimmunity against skeletal muscle in the presence of appropriate adjuvant signals (27). However, IIMs are rare diseases, suggesting that effective constraints physiologically restrict the onset of autoimmune response in skeletal muscle. These constraints have only been partially identified at the molecular level.

In healthy mouse skeletal muscle, PTX3 mRNA has been described to be undetectable. PTX3 is expressed within $4 \mathrm{~h}$ of LPS intravenous injection and is then rapidly downregulated; PTX3 mRNA is upregulated in vitro in proliferating and differentiated myoblasts in response to IL1 $\beta$ (28).

Cardiotoxin (CTX) is a depolarizing snake venom that causes myofiber death (29). Muscle injury causes acute inflammation and activates a regenerative response, which depends on satellite cells located under the basal lamina of muscle fibres, which proliferate, differentiate and fuse to yield new fibers (30). The inflammatory response and activation of muscle stem cells are intermingled (31). Here we relied on gene-modified animals and functional assays to assess contribution of PTX3 to the cross-talk between muscle necrosis, inflammation and regeneration.
Our results reveal a nonredundant role of PTX3 in the clearance of cell debris at the site of muscle injury and in the healing of injured tissue.

\section{MATERIALS AND METHODS}

\section{Acute Sterile Muscle Damage}

WT and $\mathrm{PTX}^{-/-}$C57BL/6 female mice (Charles River Laboratories) were used at $8-10$ wks of age according to European Union guidelines and with approval of the institutional animal care and use committee of our institution (No. 512). Generation and characterization of PTX3-deficient mice have been previously described (32). Mice were back-crossed to the C57BL/ 6 strain (B6, Charles River Laboratories) to the N11 generation. Mice were injected intramuscularly in the quadriceps with CTX $(10 \mu \mathrm{M}, 100 \mu \mathrm{l}$, Sigma-Aldrich) and euthanized before and at 1, 3, 5, 7, 10, 15 and $30 \mathrm{~d}$ following injury. Muscles were collected and frozen in liquid nitrogen. For immunofluorescence, muscles were eventually fixed in $4 \%$ paraformaldehyde (PFA) and treated with sucrose 30\% before freezing $(33,34)$.

\section{Histology and Immunofluorescence}

Muscle damage and repair were evaluated after hematoxylin and eosin (H\&E) staining using $10 \mu \mathrm{m}$ thick muscle cryosections. At d 7, 10, 15 and 30 after CTX injection, the fraction of central nucleated fibres per field of view (FOV) was assessed as previously described (35). Cross-sectional area measurements (CSA, d 0, 7, 10, 15 and 30 after CTX injection) were obtained using a digitized imaging system (ImageJ 1.38; National Institutes of Health) and at least 10 FOVs were counted for each mouse $(20 \times$ magnification). For immunofluorescence, sections were permeabilized with $0.1 \%$ Triton X-100 and nonspecific binding blocked by treatment with $5 \%$ bovine serum albumin (BSA) in phosphate-buffered solution (PBS) for $1 \mathrm{~h}$ at room temperature. Sections were then incubated with rabbit anti-PTX3 $(2 \mu \mathrm{g} / \mathrm{mL})$, rat anti-CD31 (5 $\mathrm{gg} / \mathrm{mL}$, Abcam), rat
anti-CD68 (0.15 $\mu \mathrm{g} / \mathrm{mL}$, Biorad), chicken anti-laminin $(1,5 \mu \mathrm{g} / \mathrm{mL}, \mathrm{DAKO})$, rabbit anti-laminin ( $5 \mu \mathrm{g} / \mathrm{mL}$, SIGMA) and rabbit anti-fibrin $(3.2 \mu \mathrm{g} / \mathrm{mL}, \mathrm{DAKO})$ antibodies in PBS and 2\% BSA overnight at $4^{\circ} \mathrm{C}$. Sections were then incubated with Alexafluor 488-conjugated anti-rat ( $4 \mu \mathrm{g} / \mathrm{mL}$, Invitrogen) and/or Alexafluor 647-conjugated anti-chicken $(4 \mu \mathrm{g} / \mathrm{mL}$, Invitrogen) or with Alexafluor 594conjugated anti-rabbit ( $4 \mu \mathrm{g} / \mathrm{mL}$, Invitrogen) antibodies for $1 \mathrm{~h}$ at room temperature. Dead cells were detected using the in situ cell death detection kit (TUNEL assay, Roche), according to the manufacturer's instructions. To evaluate PTX3 expression and macrophage infiltration by immunohistochemistry, frozen muscle sections were fixed in PFA 4\%, washed with PBS and treated with $0.3 \%$ hydrogen peroxide. Sections were then incubated with an avidin-biotin blocking reagent (Vector Laboratories), according to the manufacturer's instruction. Sections were permeabilized with $0.1 \%$ Triton $\mathrm{x}-100$ and blocked with 5\% BSA in PBS for $1 \mathrm{~h}$ at room temperature. Then sections were incubated with rabbit anti-PTX3 antibody (final concentration $2 \mu \mathrm{g} / \mathrm{mL}$ ), rat anti-mouse CD68 $(0.15 \mu \mathrm{g} / \mathrm{mL}$, Biorad) or rabbit anti-mouse caspase 3 (1:50 dilution, Cell Signaling) antibodies. Primary antibodies were revealed using biotin-conjugated anti-rabbit or anti-rat immunoglobulin (eBiosciences) and horseradish peroxidase-streptavidin (Vector Laboratories) and Vector NovaRED substrate kit (Vector Laboratories). Slides were counterstained with hematoxylin. We quantified macrophages and dead cells as the number of $\mathrm{CD}^{+} 8^{+}$and caspase $3^{+}$cells per FOV, respectively. We evaluated 20 sections for each mouse (20 $\times$ magnification). Slides were processed in parallel for immunofluorescence and immunohistochemistry using unrelated isotype-matched control antibodies. Samples were mounted using a mixture of glycerol and water (1/1, vol/vol).

Evans blue (1\% solution injected at $1 \%$ volume relative to body mass) was administered $24 \mathrm{~h}$ prior to tissue sampling. 
Image J digitized imaging system was used for quantification and at least 30 FOVs were counted for each sample (20 $\times$ magnification) $1 \mathrm{~d}$ after CTX injection. Images were captured with a Nikon Digital Sight DS-5M camera and a Nikon Eclipse 55i microscope or with a Perkin Elmer UltraVIEW ERS laserscanning confocal microscope. Linear adjustments of the images were done using Adobe Photoshop CS4.

\section{RNA Extraction and Quantitative RT-PCR}

RNA was extracted from muscles using TRIzol (Applied Biosystems), following the manufacturer's recommendations. Complementary DNAs were prepared from $1 \mu \mathrm{g}$ of RNA by the high-capacity cDNA Reverse Transcription Kit (Applied Biosystems), according to the manufacturer's instructions. Quantitative reverse transcription polymerase chain reaction (qPCR) was carried out using SYBR-green PCR Master Mix (Applied Biosystems) on an ABI7400 (Applied Biosystems). Transcripts of target genes were quantified relative to the abundance of glyceraldehyde phosphate dehydrogenase (GAPDH) by the changein-threshold method. Sequences of primers used were:

CD163: 5' GGGCTCCGTCTGTGATTTT 3' forward, 5' ACTACGCTGACATCCC TGCT 3' reverse; CD36: 5' TGACAAAG AGACCGCAAATC $3^{\prime}$ forward, 5' ACC AAGCCAAAGAACACACC $3^{\prime}$ reverse; MFG8: 5' ATCTACTGCCTCTGCCCTGA 3' forward, 5' CCAGACATTTGGCA TCATTG 3' reverse; Gas6: 5' GCCA AGATGTGGACGAGTG 3' forward, 5'TCAAAAGTGCGGAAGTCAAA 3' reverse; Mer: 5' TGATGGCTACTCCCCACTTC 3 ' forward, 5' TCTCATTCCGACAGGACACA $3^{\prime}$ reverse; GAPDH: 5' TCCACTCATGGCAAATTCAA 3' forward, 5' TTTGATGTTAGTGGGG TCTCG 3' reverse; MyoD: 5' ACGGCT CTCTCTGCTCCTTT 3' forward, 5' GTAGGGAAGTGTGCGTGCT 3' reverse; myogenin: 5' GACATCCCCCTAT TTCTACCA 3' forward, 5' GTCCCCAG TCCCTTTTCTTC 3' reverse.

\section{Western Blot}

Muscles of WT and $P T X 3^{--}$mice were isolated and homogenized as described (27). Lysates were then resolved by sodium dodecyl sulfate electrophoresis (10\% acrylamide gels) and transferred. Appropriately blocked nitrocellulose membranes were incubated overnight with anti-MyoD antibody (1:200, Santa Cruz Biotechnology) and anti-myogenin antibody (1:500, F5D, Developmental Studies Hybridoma Bank), followed by anti-mouse or -rabbit horseradish peroxidase-conjugated secondary antibody (Biorad). In parallel, blots were probed with mouse anti-mouse GAPDH (1:10000, Sigma) or rabbit anti-mouse tubulin (1:200, Abcam) antibody as a reference for protein loading. Samples to evaluate myogenin and MyoD expression were loaded on different gels and normalized against GAPDH or tubulin using ImageJ.

\section{Retrieval and Characterization of CD45 Muscle-Infiltrating Leukocytes}

Infiltrating cells were retrieved from damaged muscles at $d$ 1, 3, 7, 10 and 15 after CTX by enzymatic digestion using collagenase type V (Sigma, $0.5 \mathrm{mg} / \mathrm{mL}$ ) and dispase (Invitrogen, $3.5 \mathrm{mg} / \mathrm{mL}$ ) at $37^{\circ} \mathrm{C}$ for $40 \mathrm{~min}$. Single cells obtained from quadriceps muscle digestion were counted and analyzed by flow cytometry after isolation by CD45 magnetic beds (Miltenyi Biotech). Cells were incubated with PerCP-conjugated anti-CD45 (Clone 30-F11, BD Biosciences), PE-conjugated anti-F4/80 (Clone BM8, Biolegend) and FITC-conjugated Ly6G (Clone 1A8, Biolegend) antibodies and analyzed using a FACS Canto apparatus (BD Biosciences). Analysis was performed with FlowJo software (Treestar).

\section{Bone Marrow-Derived Stem Cell Transplantation}

Bone marrow cells were harvested by flushing the femurs and tibias of $P T X 3^{--}$ mice (C57B / 6 CD45.2 background) and injected $\left(1 \times 10^{7}\right.$ cells /mouse $)$ into sublethally irradiated (7 cGy) congenic C57BL/ 6 CD 45.1 ${ }^{+}$WT mice, as described
(36). Pooled bone marrow cells derived from five donors were transplanted into 15 recipient animals. Mouse muscles were then injected with CTX as described above and analyzed 5, 7 and $10 \mathrm{~d}$ later.

\section{Phagocytosis of Apoptotic Cells}

Macrophages were derived from WT and $\mathrm{PTX}^{-/-}$bone marrow precursors and cultured for $7 \mathrm{~d}$ in $\alpha$-MEM (GIBCO, Invitrogen) containing 10\% fetal calf serum, antibiotic and glutamine in the presence of recombinant murine M-CSF (100 ng/mL, Miltenyi Biotech) (37). Phagocytosis of apoptotic cells was assessed as described (16). For apoptosis induction, RMA cells were plated $\left(5 \times 10^{5}\right.$ cells $\left./ \mathrm{mL}\right)$ in RPMI medium, $10 \%$ fetal calf serum, antibiotics and glutamine. Cells were then irradiated using a UV source at $0.1 \mathrm{~J} / \mathrm{cm}^{3}$. After $16 \mathrm{~h}$, an aliquot of cells was labeled with FITCconjugated Annexin-V (Bender MedSystems) and propidium iodide to verify death of cells and assess the externalization of phosphatidylserine. UV-treated RMA cells were then stained with CMTMR (5-(and-6)-((4-chloromethyl) benzoyl) amino) tetramethylrhodamine, Invitrogen) according to the manufacturer's instructions. Staining of cells was then verified by cytofluorimetric analysis. For phagocytosis experiments, apoptotic-CMTMR-labeled RMA cells were incubated with macrophages at a 1:1 or 1:2 ratio (macrophages: apoptotic cells) at $37^{\circ} \mathrm{C}$ for $2 \mathrm{~h}$ before analysis by flow cytometry using a FACS Canto apparatus, and analyzed by FlowJo software. Macrophages were identified by staining with APC-conjugated anti-CD11b (Clone M1/70, BD Bioscience). Parallel experiments were performed incubating macrophages and apoptotic RMA cells at $4^{\circ} \mathrm{C}$ for $2 \mathrm{~h}$ (i.e., a condition in which particulate substrates are not actively internalized).

\section{Autoantibody Detection and Quantification}

IgG anti-HisRS antibodies in the serum were measured using standard 
solid-phase enzyme-linked immunosorbent assay (ELISA) as previously described (27) and expressed as optical density (OD) values at $450 \mathrm{~nm} \pm$ standard deviation (SD). Sera were obtained 7,14 and $21 \mathrm{~d}$ after damage from untreated and CTX-damaged WT or $\mathrm{PTX}^{-/-}$ mice. IgG anti-HisRS antibody values were compared with those obtained for WT animals damaged with CTX and immunized with apoptotic HisRS-expressing myoblasts in presence of the Toll-like receptor agonist R848 (27). Serum dilution was 1:16.

\section{Statistics}

Data are expressed as means \pm standard error of the mean (SEM) or SD. Statistical analysis was performed using two-tail Student $t$ test for unpaired data, or one-way analysis of variance (ANOVA) when appropriate. Values of $p<.05$ were considered statistically significant.

All supplementary materials are available online at www.momed.org.

\section{RESULTS}

PTX3 expression is upregulated in regenerating skeletal muscle upon acute sterile injury. Muscles were acutely injured by local injection of the depolarizing toxin CTX. Sections of healthy muscle and of muscle retrieved 1, 3, 5 and $7 \mathrm{~d}$ after injury were analyzed for PTX3 expression. Scattered endothelial cells expressed PTX3 in healthy muscle (Figures 1A and S1). PTX3 expression remained negligible $1 \mathrm{~d}$ after injury (Figure 1B) and briskly increased at d 3 and 5 (Figures 1C and D). PTX3 expression was mainly restricted to the provisional extracellular matrix surrounding myofibers. It decreased at later time points (see d 7, Figure 1E).

To identify the source of PTX3 in regenerating muscle, we retrieved inflammatory cells that infiltrated the tissue at various times after injury. $\mathrm{Ly} 6 \mathrm{G}^{+}$ neutrophils were abundant at $d 1$, when PTX3 was not detectable in the tissue; the number decreased at later time points

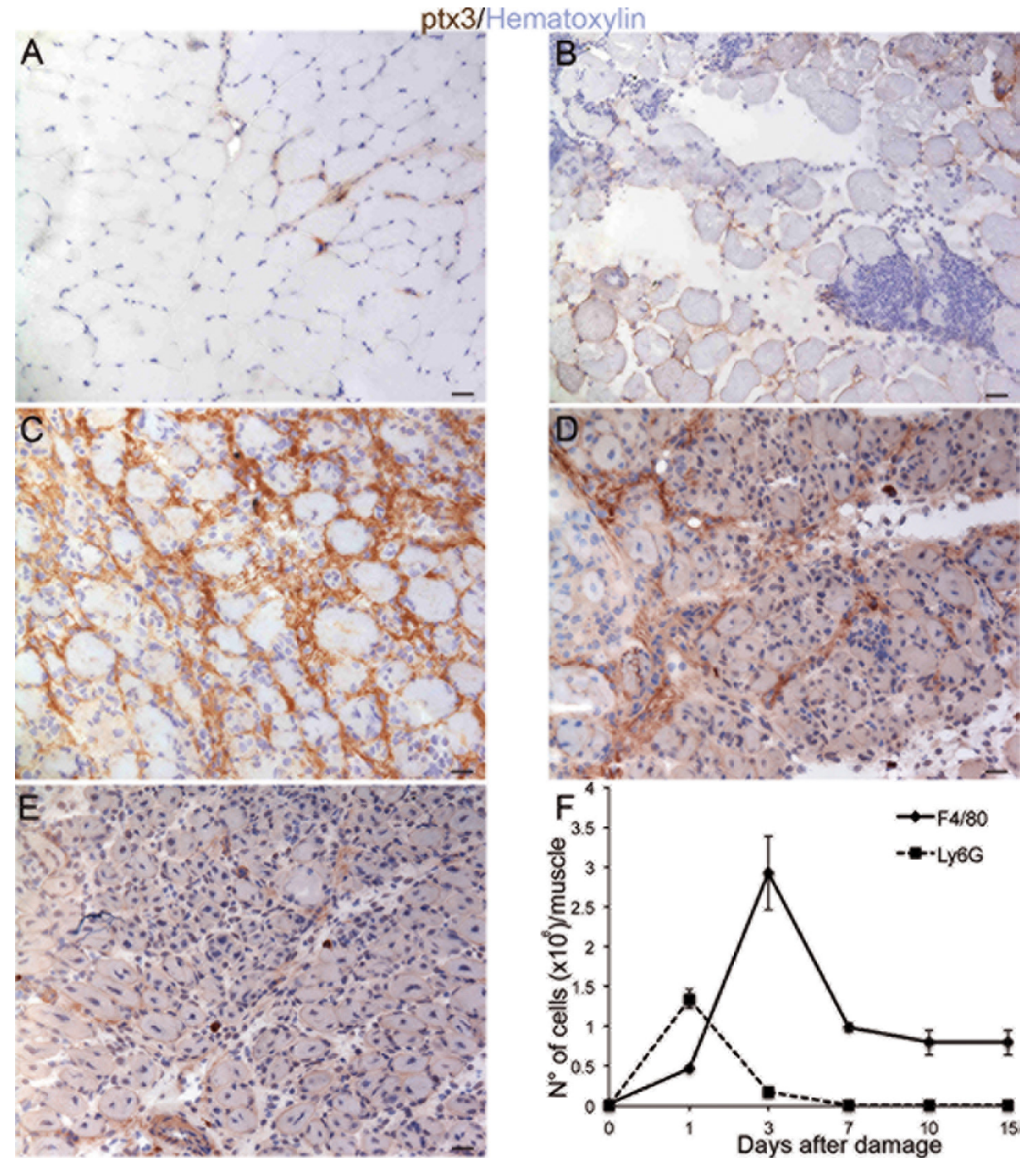

Figure 1. PTX3 accumulates in the extracellular matrix of injured and regenerating skeletal muscles. PTX3 expression was assessed by immunohistochemistry, in sections of WT mouse quadriceps muscles isolated (A) before and (B) 1, (C) 3, (D) 5 and (E) 7 $\mathrm{d}$ after injury. Hematoxylin stained nuclei. Scale bars $=20 \mu \mathrm{m} ; n=15$ (three mice/time point). Three independent experimental cohorts were studied. (F) CD45 cells were retrieved from WT mouse quadriceps muscles by enzymatic digestion at various times after injury, and the number of $\mathrm{F} 4 / 80^{+}$(black line) and $\mathrm{Ly}_{6 \mathrm{G}}{ }^{+}$(dashed line) were assessed. Results are expressed as mean \pm s.e.m; $n \geq 15$ (three-five mice/time point) per three independent experimental cohort.

(Figure $1 \mathrm{~F}$, dashed line). F4/80 ${ }^{+}$macrophages were mostly represented $3 \mathrm{~d}$ after injury and decreased thereafter (Figure 1F, black line), consistent with the kinetics of PTX3 expression.

PTX3 expression by infiltrating macrophages was investigated in situ by immunofluorescence. Five days after CTX, infiltrating $\mathrm{CD}^{+} 8^{+}$macrophages and CD68 interstitial cells both expressed PTX3 (Figure 2A, arrows and asterisks, respectively). The contributions of bone marrow-derived inflammatory leukocytes and tissue-resident interstitial cells to PTX3 expression in the injured muscle was also evaluated using CD45.1 WT mice transplanted with CD45.2 $\mathrm{PTX}^{+/+}$or $\mathrm{PTX}^{-/-}$bone marrow precursors 
(Figures 2B and C). Five days after injury, PTX3 expression was clearly detectable in mice transplanted with $\mathrm{PTX}^{-/}$bone marrow cells (Figure 2C), suggesting that both recruited bone marrow-derived and resident cells contribute to the expression of PTX3 in injured skeletal muscle.

\section{PTX3 Expression Is Required for Muscle Regeneration}

Quadriceps muscles of WT and $\mathrm{PTX}^{-/-}$mice were injured by local injection of CTX. Muscle isolated before and 1, 3, 7, 10, 15 and $30 \mathrm{~d}$ after injury were analyzed and compared. The architecture of healthy muscle of WT and PTX3 $3^{-/-}$mice was similar (Figure S2A) and the area of fibers was not statistically different (Figure S2B). After CTX injection, WT and $\mathrm{PTX}^{-/-}$mice had a similar extent of early fiber damage (Figures S2C and D) and infiltration by inflammatory leukocytes (Figure S2E), suggesting that sensitivity to the toxin is not greatly altered in the absence of PTX3.

Seven days after injury, the inflammatory infiltrate was greatly reduced in WT mice and regenerating fibers (with the typical central nuclei) were abundant (Figure 3A). Infiltration by inflammatory leukocytes was still prominent at this time point in injured muscle of $P T X 3^{-/}$ mice, while the number of regenerating fibers was low (Figures 3B and C).

Ten days after injury, inflammatory cells were not detectable in WT muscle (Figure 3D). In sharp contrast, at this time point inflammatory leukocytes infiltrated muscle (Figure 3E) while regeneration was limited in $\mathrm{PTX}^{-/-}$mice (Figure $3 \mathrm{~F}$ ).

Fifteen days after CTX damage (Figures 3G and I), regeneration was prominent in WT mice, with no remaining signs of inflammation. In contrast, uncleared cell debris, disrupted tissue architecture inflammation and reduced regenerating fibers characterized muscle of $\mathrm{PTX}^{-/-}$mice (Figures $3 \mathrm{H}$ and I). Thirty days after injury, the muscle of WT mice healed (Figures $3 \mathrm{~K}$ and J). Uncleared cell debris and regeneration characterized muscle of $\mathrm{PTX}^{-/-}$mice (Figures 3L and $\mathrm{J}$ ), indicating that PTX3 expression
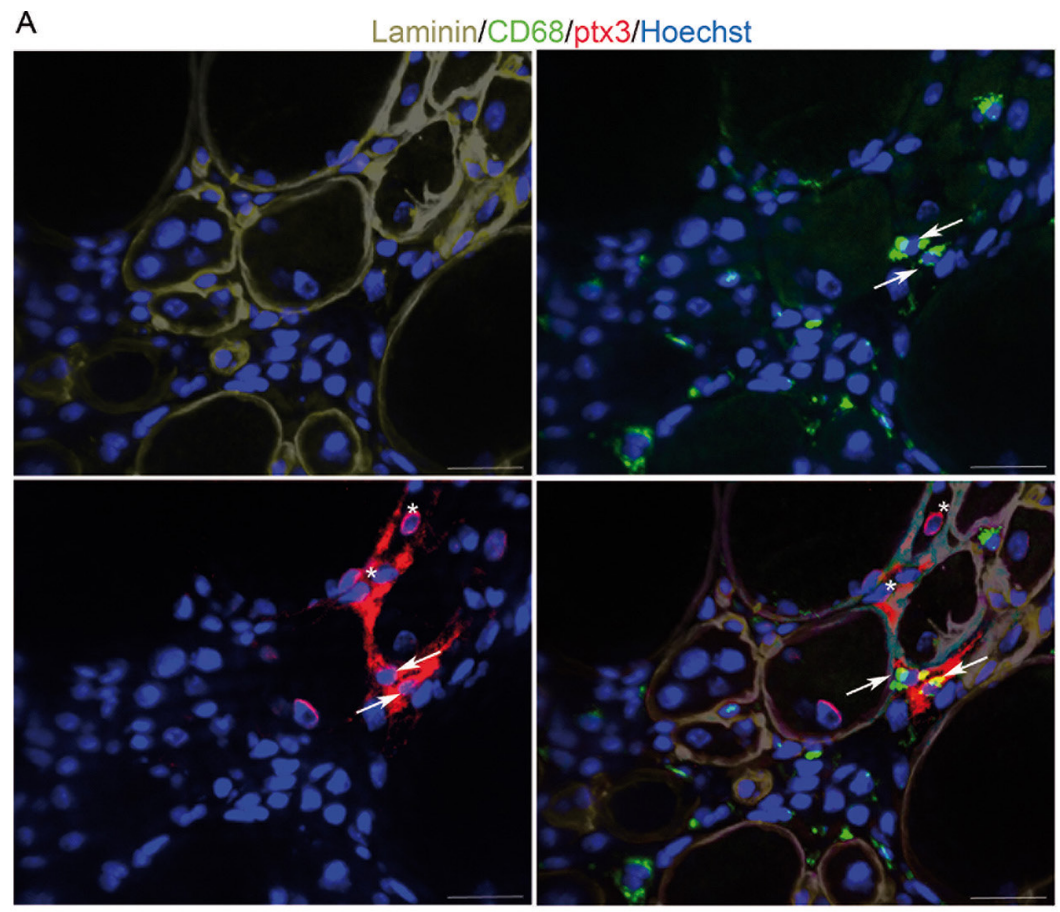

B

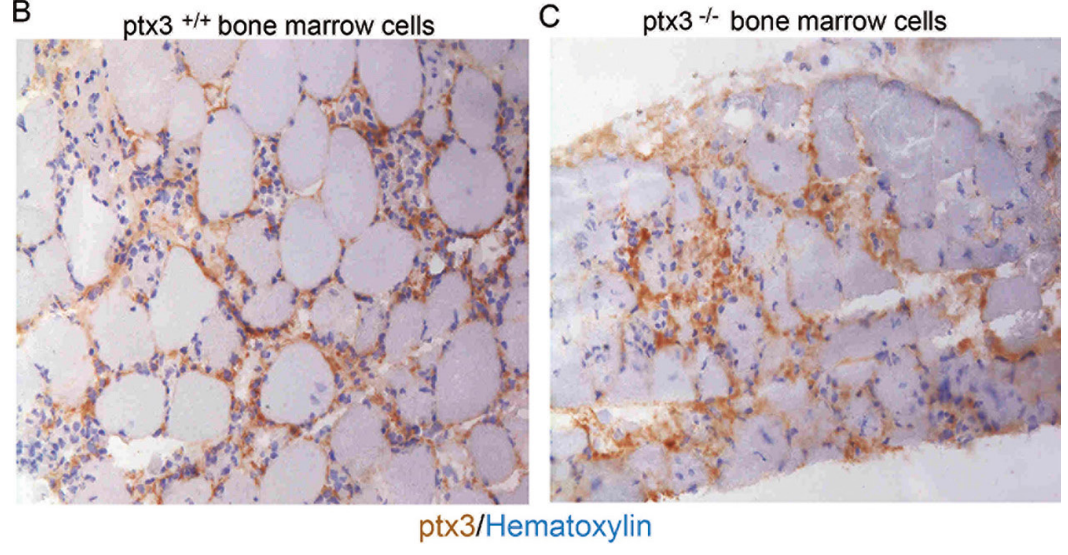

Figure 2. PTX3 expression by infiltrating macrophages and stromal cells. PTX3 expression was assessed in sections of WT mouse quadriceps muscles $5 \mathrm{~d}$ after CTX injury. (A) Immunofluorescence staining for CD68 (green), PTX3 (red) and laminin (gray) expression. Some CD68 ${ }^{+}$cells expressed PTX3 (arrows), but PTX3 was also present in provisional matrix and in CD68 cells (asterisks). Hoechst stained nuclei; scale bars $=20 \mu \mathrm{m} ; n=9$; three mice per three independent experimental cohorts were studied. PTX3 expression was evaluated by immunohistochemistry in sublethally irradiated mice transplanted with (B) PTX $3^{+/+}$or (C) PTX ${ }^{-/}$bone marrow cells $5 \mathrm{~d}$ after CTX injection. Scale bars $=20 \mu \mathrm{m} ; n=15$, three mice per five independent experimental cohorts were studied.

is required for effective and timely healing of the tissue. The clearance of debris and the kinetics of regeneration were apparently conserved after injury of the muscles of WT mice lethally irradiated and transplanted with $P T X 3^{-1}$ bone-marrow progenitors (Figure S3).
The extent and kinetics of expression of the myogenic transcription factors MyoD and myogenin after injury in the presence or absence of PTX3 were similar (Figures 4A and B). In agreement, the cross-sectional area of regeneration myofibers did not differ in WT and $\mathrm{PTX3}^{-/}$ 

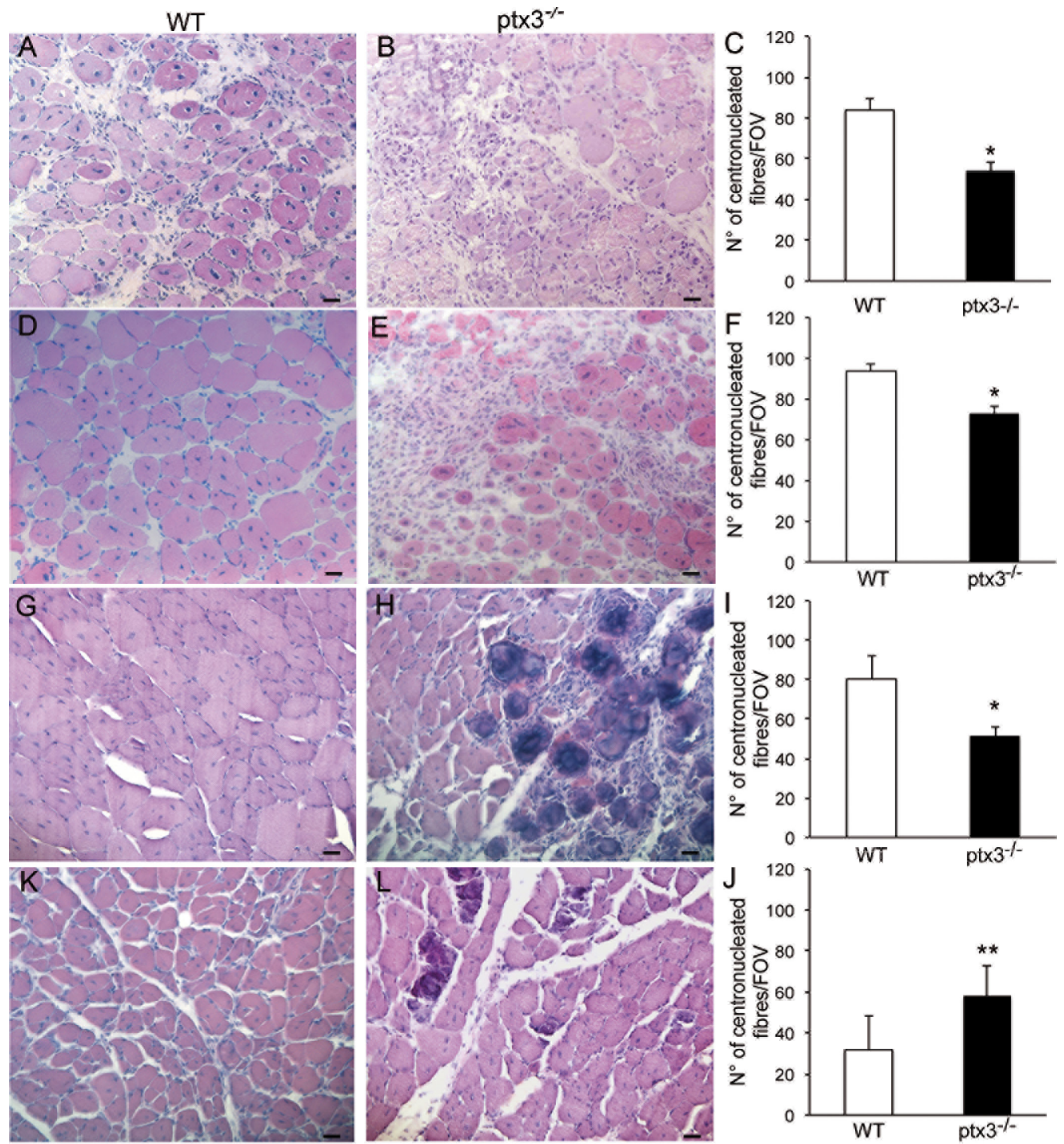

Figure 3. PTX3 plays a nonredundant role in the inflammatory response and regeneration from sterile muscle injury. Quadriceps muscles were retrieved from (B-L) PTX $3^{-1}$ mice at (A, B) 7, (D, E) 10, (G, H) 15, and (K, L) 30 d after CTX injury. Muscle sections were stained by H\&E. The number of centronucleated fibers was counted at (C) 7, (F) 10, (I) 15 and (J) $30 \mathrm{~d}$ after injury and expressed as number/FOV. $\mathrm{n} \geq 9$ (two-three mice/time point for both WT and PTX $3^{-1-}$ mice). Three independent experimental cohorts were studied. ${ }^{*},{ }^{* *}$ : significantly different from WT mice, ${ }^{*}=P<.05$ or ${ }^{* *}=P<.01$ (Student $t$ test). Graphs show mean values \pm s.d. Scale bar $=20 \mu \mathrm{m}$. 

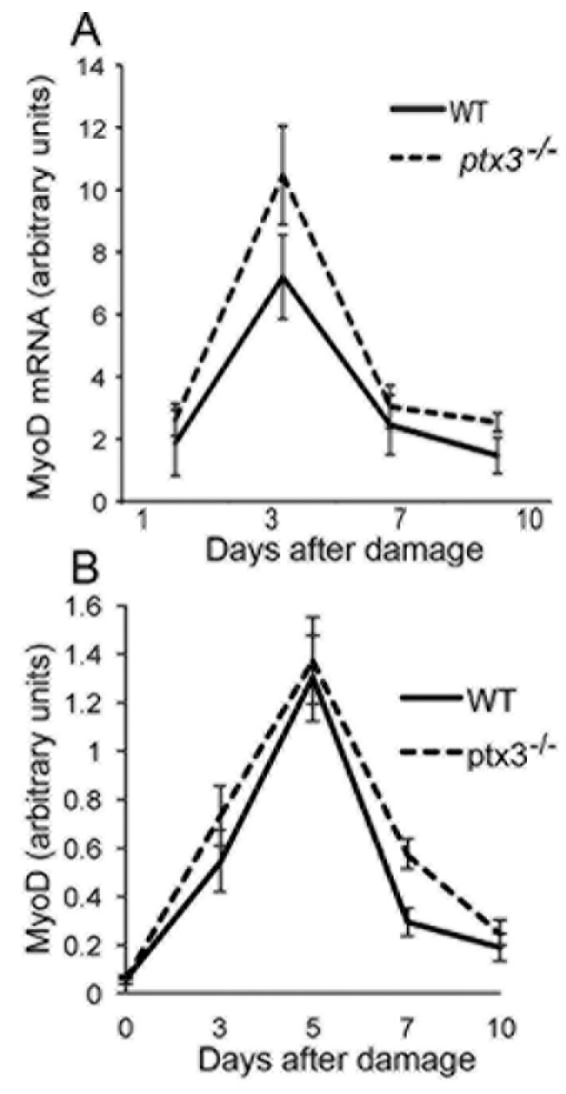

C

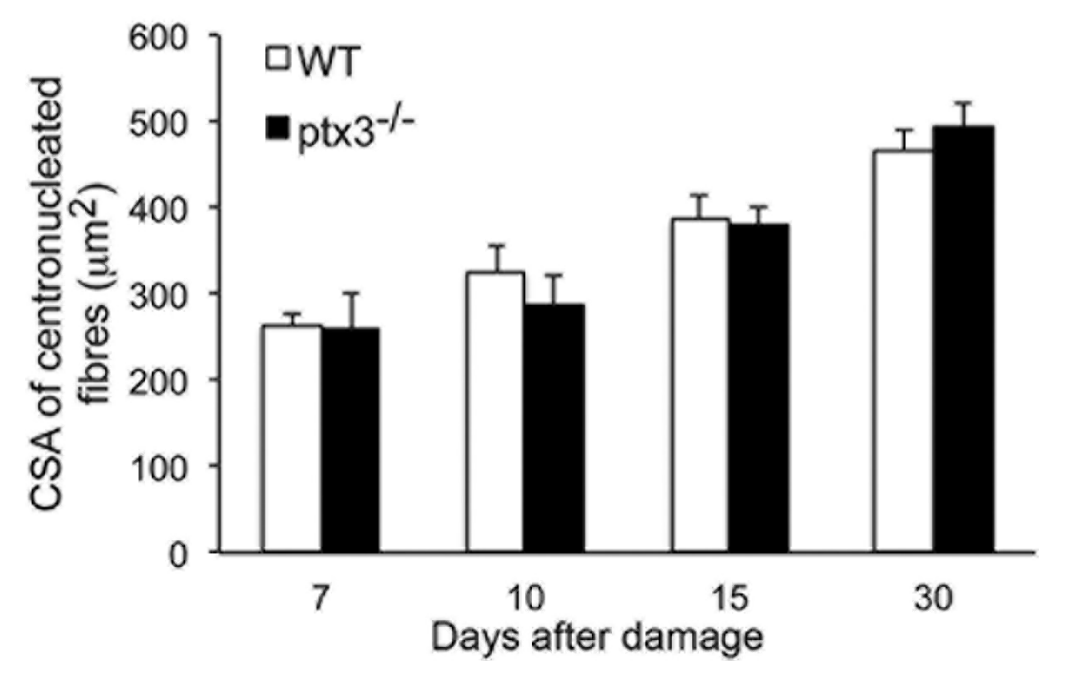

Figure 4. PTX3 expression is required for timely termination of the muscle regenerative response. Kinetic expression of MyoD (left) and myogenin (right) was evaluated by (A) RT-PCR or (B) Western blot in quadriceps muscles of WT (black line) and PTX $3^{-1}$ mice (dashed line) after CTX injection. $n \geq 12$ mice (two-three mice/time point for WT and $\mathrm{PTX}^{-/}$mice; analyses were performed in triplicate). Three independent experimental cohorts were studied. (C) The myofiber cross-sectional area (CSA) was compared in muscle of WT and $P T X 3^{-1-}$ mice retrieved $7,10,15$ and $30 \mathrm{~d}$ after injury. $n \geq 9$ mice; three independent experimental cohorts were studied. Graphs show mean values \pm (A, B) s.e.m or (C) s.d. mice (Figure 4C). Fibrin deposition in the provisional extracellular matrix surrounding regenerating fibers after CTX injury was low and apparently similar in WT and $\mathrm{PTX}^{-/-}$muscle (Figure S4).

Persistence of inflammation and accumulation of cell debris in injured $\mathrm{PTX3}^{-/-}$muscles do not induce tolerance breakdown. TUNEL ${ }^{+}$nuclei were virtually absent in the muscle of WT mice $15 \mathrm{~d}$ after injury. In contrast, we consistently found accumulation of TUNEL ${ }^{+}$ apoptotic cells in the muscle of $P T X 3^{-/-}$ mice (Figures S5A and B). Fifteen days after injury, the number of cells expressing activated caspase 3 was strikingly and significantly lower in the quadriceps muscle of WT mice than $P T X 3^{-/-}$mice $(p<.005$, Figures $5 \mathrm{~A}-\mathrm{C})$. At this time point, relatively few $\mathrm{CD}^{-} 8^{+}$macrophages were detectable in the WT muscle (Figure 5D) that had completed debris scavenging. In contrast, they abundantly infiltrated the muscle of $\mathrm{PTX}^{-/-}$mice where they are preferentially located in the proximity of remnants of damaged myofibers (Figure 5E, quantitative data in 5F). Immunization with apoptotic myoblasts in the presence of the R848 adjuvant triggers the production of autoantibodies recognizing the HisRS auto-antigen in CTX-treated WT mice (OD $0.556 \pm 0.086$ at $\mathrm{d} 7$ after treatment versus $0.287 \pm 0.103$ in untreated mice; $n \geq 5$ ). The accumulation of cell remnants in an inflammatory environment that occurs in $P T X 3^{-/-}$mice thus represents a potential trigger of the generation of autoantibodies. However, we did not observe any difference in the spontaneous production of anti-HisRS autoantibodies in WT or $\mathrm{PTX}^{-/-}$mice $(0.309 \pm 0.0963$ OD arbitrary units versus $0.293 \pm 0.041$ OD arbitrary units at $\mathrm{d} 7$; $n \geq 5$ ). OD values did not differ from the background values observed in the blood of untreated animals. No difference between WT and $\mathrm{PTX}^{-/-}$ mice was observed even at later time points $(0.177 \pm 0.049$ for WT and $0.211 \pm$ 0.057 OD A.U. for PTX $^{-/-}$mice at $14 \mathrm{~d}$; $0.104 \pm 0.031$ for $\mathrm{WT}$ and $0.117 \pm 0.0470$ OD A.U. for $\mathrm{PTX3}^{-/-}$mice at $21 \mathrm{~d}$ ). 
A

B

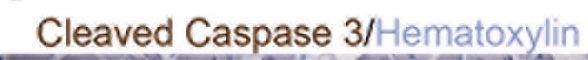

B
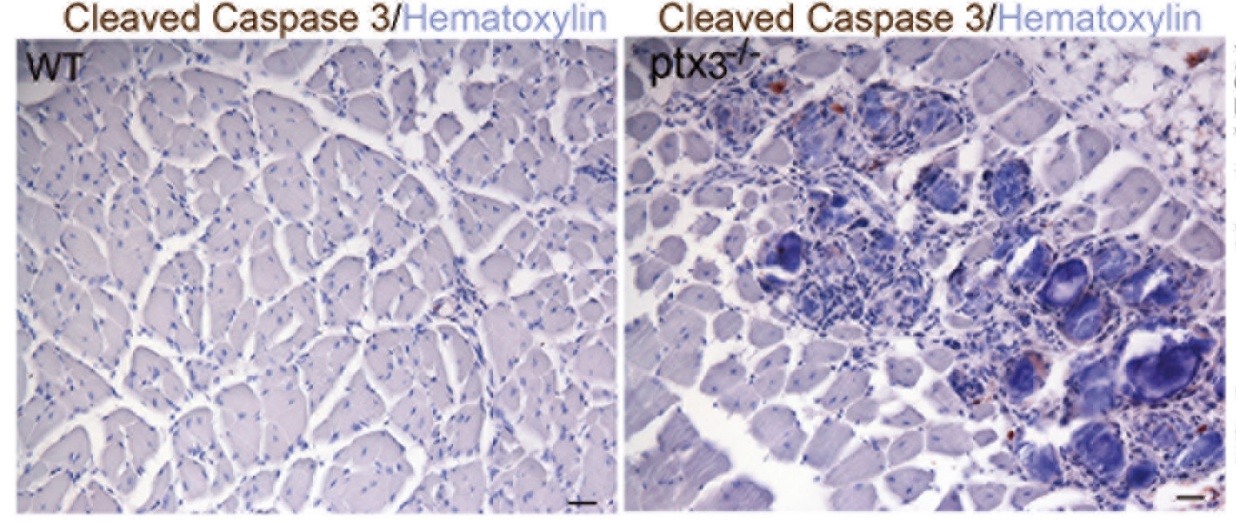

C
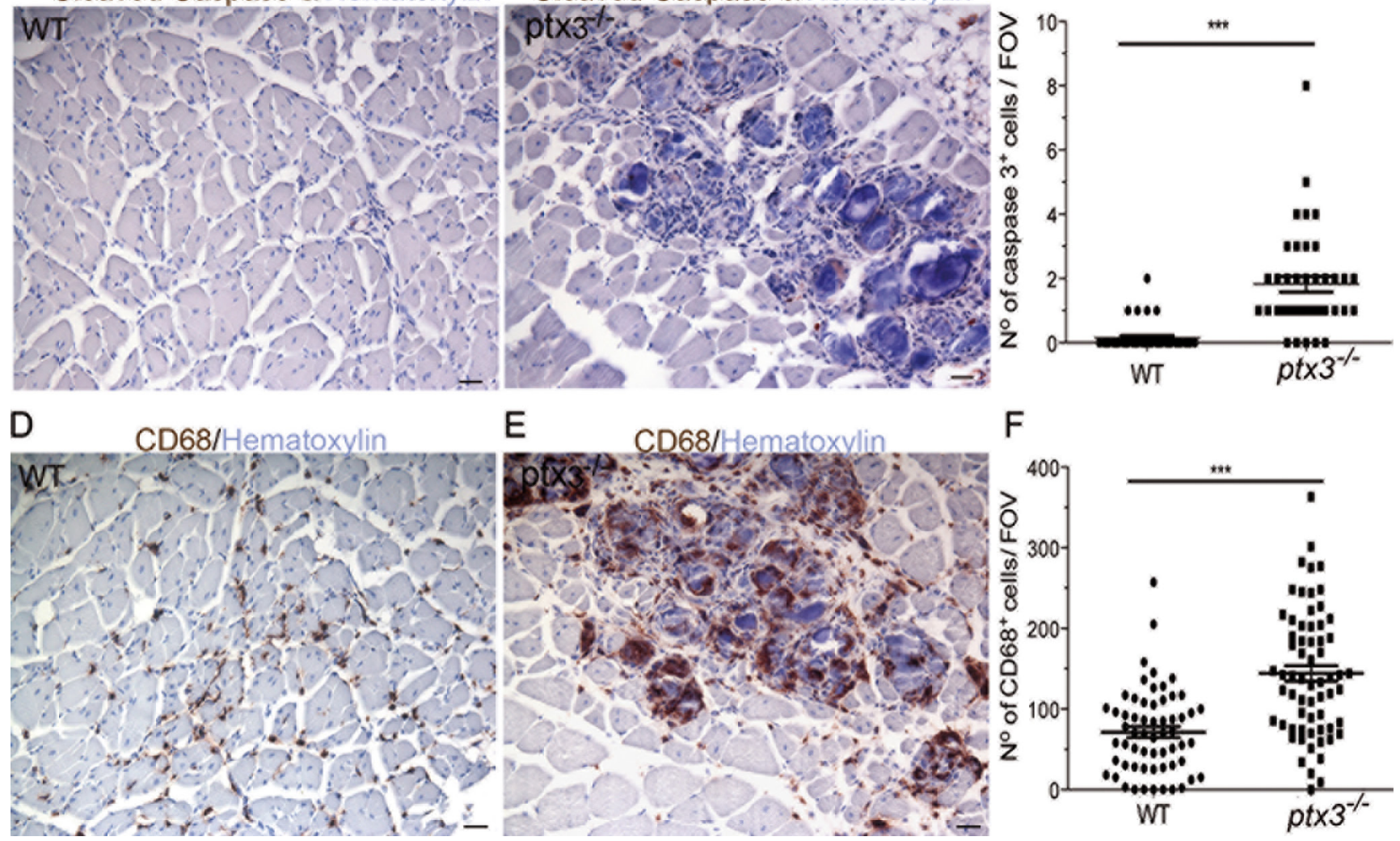

$\mathrm{F}$

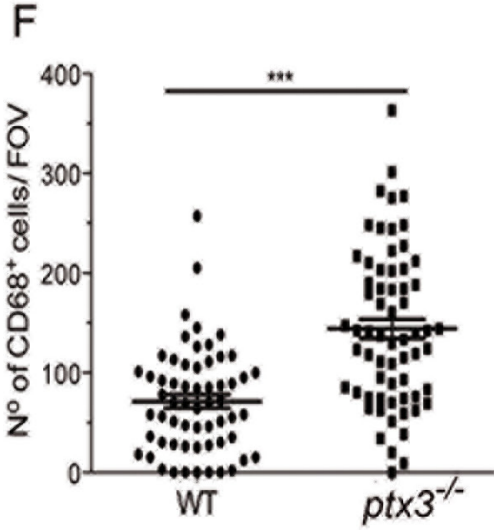

Figure 5. Accumulation of myofiber remnants and muscle infiltration by macrophages in the absence of PTX3. Quadriceps sections of mouse muscle were analyzed $15 \mathrm{~d}$ after injury. Representative images of cleaved caspase 3 in (A) WT and/or (B) PTX $3^{-/-}$mice assessed by immunohistochemistry. (C) Number of cells expressing cleaved caspase 3 per FOV for WT and/or PTX $3^{-/-}$mice. Representative images for CD68 in (D) WT and/or (E) PTX3 $3^{-/-}$muscle assessed by immunohistochemistry. (F) Number of cells expressing CD68 per FOV for WT and/or PTX ${ }^{-/}$mice. $n \geq 9$. Three independent experimental cohorts were studied. Graphs show mean values $\pm s . d .{ }^{* * *}:$ significantly different from WT mice, $P<.005$ (Student $t$ test). Scale bars $=20 \mu \mathrm{m}$.

The ability of macrophages to phagocytose apoptotic cells is maintained in the absence of PTX3. We verified whether the persistence of cellular remnants in muscles of $\mathrm{PTX}^{-/-}$mice was due to a cell autonomous defect. Phagocytes $\left(\mathrm{CD} 11 \mathrm{c}^{+}\right.$ cells) from bone marrow precursors of WT and $P T X 3^{-/-}$mice engulfed CMTMR-labeled apoptotic RMA cells with similar efficiency (Figures 6A and B). As expected, phagocytosis of apoptotic cells abated at $4^{\circ} \mathrm{C}$, i.e., a temperature that does not allow reorganization of the actin-based cytoskeleton (Figure 6B). We investigated in WT and $\mathrm{PTX3}^{-/-}$muscle the expression of molecules involved in the ability of macrophages to recognize and clear apoptotic cells. At d 3 after injury, both the expression of the receptor tyrosine kinase Mer-TK and its ligand, growth arrest-specific protein 6 (GAS-6) sharply increased. Upregulation of Mer-TK was significantly higher in the absence of PTX3, suggesting that macrophages recruited in the tissue are per se capable of recognizing the apoptotic prey and might upregulate the machinery involved in their clearance in an attempt to compensate for the frustrated phagocytosis (Figures 6C and D). The expression of the haptoglobin/hemoglobin scavenger receptor CD163, which identifies alternatively activated tissue-healing macrophages, followed similar kinetics (Figure 6E). At later time points, the tissue expression of milk-fat globule EGF factor-8 (MFG-E8), which promotes the phagocytic removal of apoptotic cells by bridging phosphatidylserine to integrin receptors on phagocytes, was also significantly higher in regenerating muscle of $\mathrm{PTX3}^{-/-}$mice (Figure $6 \mathrm{~F}$ ).

\section{DISCUSSION}

Immune cells, including antigenpresenting cells, are undetectable in skeletal muscle in physiological conditions, and the tissue expression of MHC class I molecules is limited. Moreover, the outcome of sterile injury in skeletal muscle appears to be recruitment of macrophages and T cells, which play nonredundant roles in muscle regeneration and possibly contribute to limiting of 

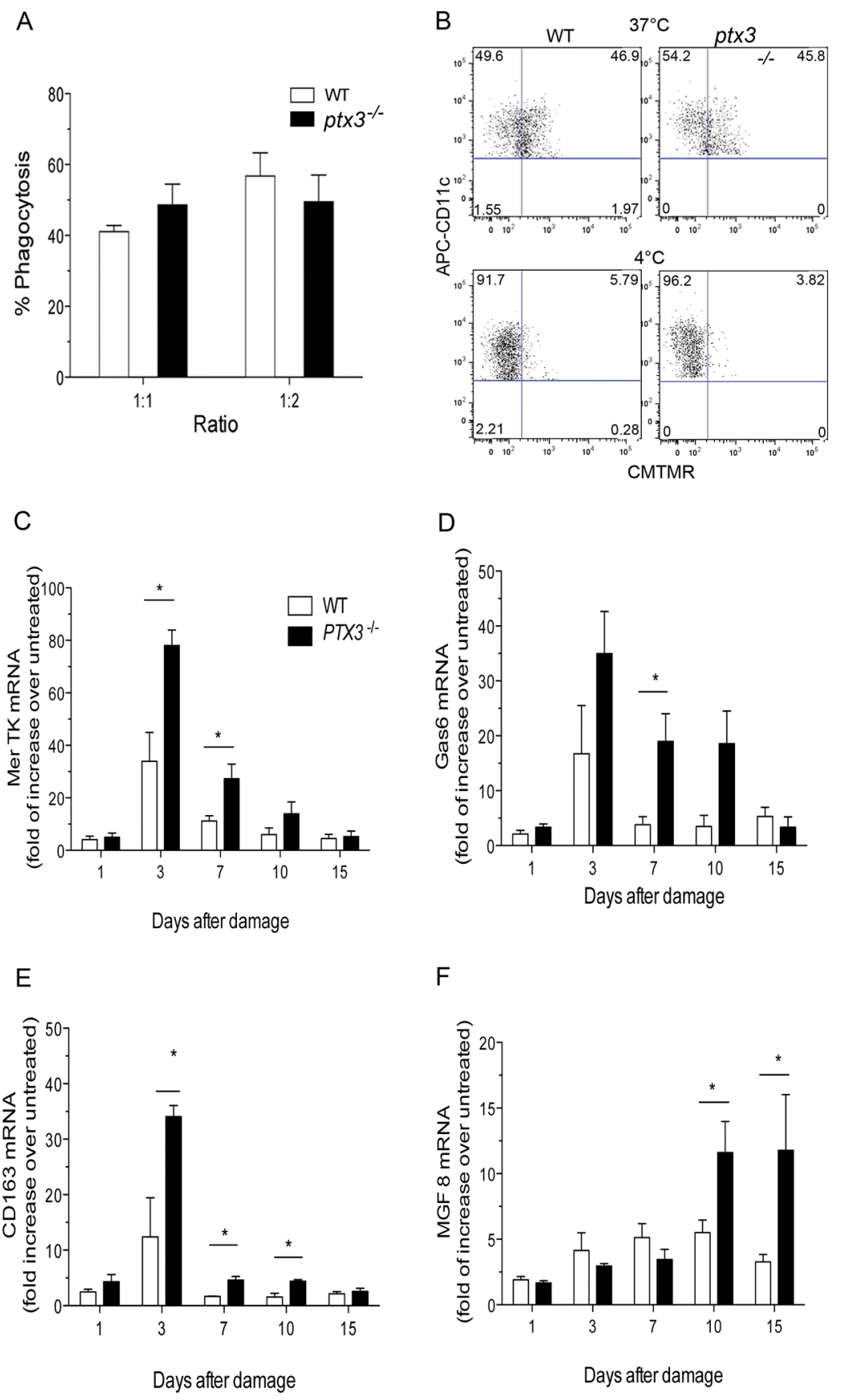

$\mathrm{D}$

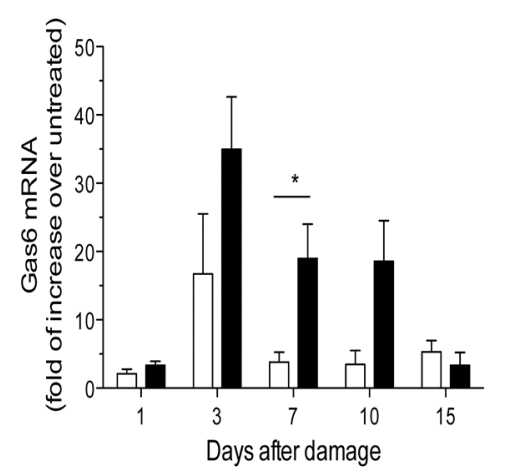

$\mathrm{F}$

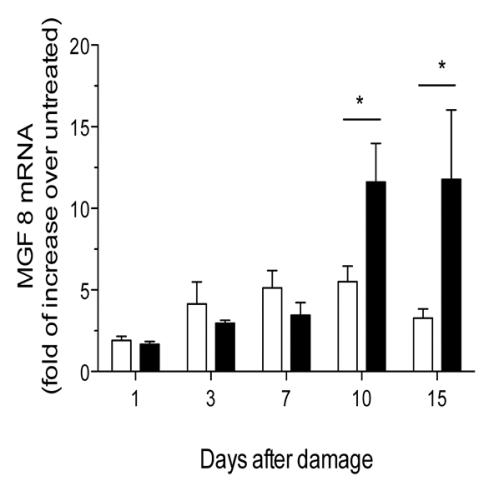

Figure 6. PTX3 deletion does not per se influence macrophage ability to recognize and phagocytose apoptotic cells. (A) The ability of macrophages propagated from bone marrow precursors of WT or PTX ${ }^{--}$mice was assessed by flow cytometry using two different phagocytes: apoptotic cell ratios are expressed as percentage of phagocytized cells. Results (mean values \pm s.e.m) are representative of three independent experiments performed in triplicate. (B) Representative dot plots of WT and PTX ${ }^{-/-} \mathrm{CD} 11 \mathrm{c}^{+}$macrophages (y axis) challenged at $37^{\circ} \mathrm{C}$ (upper panels) and at $4^{\circ} \mathrm{C}$ (lower panels) with CMTMR ( $x$ axis). Expression of (C) MerTK, (D) Gas6, (E) CD163 and (F) MFG-E8 assessed by RT-PCR in WT and PTX $3^{--}$quadriceps at $d$ 1 , 3, 7, 10 and 15 after injury. Results (mean values \pm s.e.m) are representative of at least three independent experiments $(n \geq 15$, at least three mice for each time point). *: significantly different from WT mice, $P<.05$ (ANOVA).

autoimmunity $(34,38,39)$. The capacity of skeletal muscle to effectively regenerate is indeed a process that comprises early infiltration of the tissue by inflammatory phagocytes, disposal of the damaged cells and activation and differentiation of resident stem cells, in particular satellite cells (40). Here we show that, although undamaged skeletal muscles of WT and $\mathrm{PTX}^{-/-}$mice are morphologically similar, healing time upon severe sterile injury differs dramatically. Specifically, in the absence of PTX3, the inflammatory response is prolonged and muscle cell debris persists long after the tissue of WT animals has healed.

Persistent inflammation with recruitment of autoreactive $T$ cells characterizes the skeletal muscle in idiopathic inflammatory myopathies (41). Commonly targeted autoantigens are proteins involved in DNA transcription or protein synthesis, such as HisRS. Modifications of autoantigens, including altered distribution and/or access to phagocytes for processing, might be mechanistically important (42), and signals selectively expressed during regeneration (possibly including PTX3) might influence antigen presentation. In turn, this might contribute to the onset and maintenance of autoimmune responses targeting ubiquitously expressed antigens. A striking and selective feature of $P T X 3^{-/-}$mouse damaged muscle is the accumulation of myofiber apoptotic remnants, which persist for a long time. PTX3 has been shown to bind to dying cells, particularly in the late phase of the process, and to regulate their clearance (16), possibly via interaction with other molecules of innate humoral immunity, including complement and ficolins $(3,23)$. Further studies are warranted to identify the actual reasons behind the defective removal of apoptotic material from injured and regenerating skeletal muscle. We failed to detect major defects in the expression of signals involved in apoptotic cell recognition and clearance or detectable differences in the phagocytic functions of WT or PTX3 ${ }^{-/-}$ macrophages in vitro. It is tempting to speculate that macrophages crawling 
in the matrix of regenerating muscles, in the absence of PTX3, fail to receive signals that are necessary to face the excess metabolic load associated with the clearance of apoptotic material generated as a consequence of acute sterile muscle injury (43).

We have recently observed that apoptotic myoblasts in the presence of appropriate adjuvants (activating TLR7-dependent inflammatory pathways and generation of type I interferon) are immunogenic after acute sterile injury (27). They induce production of anti-HisRS antibodies and persistent CD3-positive cell infiltration, reproducing several features of human IIM. In spite of this, accumulation of cell remnants and persistent inflammation in PTX3-null mice anti-HisRS antibodies did not develop, indicating the need for specific adjuvant signals to promote immunogenicity of the antigens associated with the cell debris.

The detailed mechanisms of the PTX3 effect on regeneration lathering require further clarification in the future. Impaired regeneration of skeletal muscle could depend on a jeopardized function of muscle stem cells (30). This is not likely, since similar kinetics of expression of MyoD and myogenin were found in $\mathrm{PTX}^{-/-}$and WT muscles during the regeneration phase, and the cross-sectional area of centronucleated fibers was similar.

Inflammatory cells recruited to the damage site essentially comprise phagocytes, such as polymorphonuclear leukocytes, and macrophages, which play a nonredundant role in sustaining satellite cell activation (44-46). Specifically, inflammatory macrophages within the regenerating tissue acquire a reparative function; this shift in turn requires phagocytosis of apoptotic cells $(46,47)$. Macrophage expression of AMPK $\alpha 1$, a master regulator of energy homeostasis, regulates both clearance of apoptotic debris within the injured muscle and acquisition of the ability to support myogenesis (48), indicating a causal link between the two phenomena.
In healthy mouse muscle, PTX3 is expressed at very low levels (28). We observed that after muscle injury, PTX3 expression remains negligible in the damaged area until 3-5 d post-injury. Al this time point, PTX3 expression clearly increased and localized into the provisional extracellular matrix around fibers. This observation agrees with a role of this soluble pattern recognition receptor in various injured tissues that involves regulation of provisional ECM assembly $(8,18)$. ECM features directly influence muscle regeneration (49), and ECM degradation products promote macrophage polarization (50), suggesting that the function of infiltrating macrophages might be influenced in injured muscle by the state of ECM.

Infiltrating macrophages represent a likely source of PTX3 in the tissue, even if not all muscle macrophages expressed PTX3. This could be explained by a rapid release of the protein at the site of injury after de novo production (51) and/or by preferential PTX3 expression in subsets of differentially activated macrophages, such as those expressing the CD163 haptoglobin/hemoglobin scavenger receptor (52). Interestingly, PTX3 expression and accumulation of CD163-expressing macrophages correlate in the plaque of patients with acute myocardial infarction (52).

Macrophages are not the only source of PTX3 in injured mouse skeletal muscle. We detected PTX3 in the muscle ECM of mice in which bone marrowderived cells failed to express the molecule, suggesting a role for stromal progenitor cells, possibly including fibroadipogenic precursors (53). Stromal cells of mesenchymal origin represent a major source of PTX3 in wounded skin (18), indicating that this is not a selective feature of injured skeletal muscle. Interestingly, PTX3 generated by stromal cells is sufficient to guide regeneration of skeletal muscle after sterile injury, indicating that local release of the molecule by inflammatory leukocytes might be partially redundant.

Most tissues have mechanisms to support effective recognition and clearance of apoptotic cells and debris. The timely expression of PTX3 in regenerating muscle appears to be one such mechanism, and to be necessary to prevent accumulation of uncleared apoptotic cells and prompt regeneration of the tissue. In spite of this, the signals that regulate muscle tolerance are regulated by a variety of signals next to the appearance of apoptotic cells. The contribution of removal of the dying cells and of signaling generated by the phagocytizing macrophages in breaking muscle tolerance remains an open question.

\section{CONCLUSION}

PTX3 generation is an integral constituent of the physiological response of skeletal muscle to sterile injury. The soluble pattern recognition receptor plays a nonredundant role in removal of cellular debris from the tissue and in timely conclusion of the inflammatory response.

\section{ACKNOWLEDGMENTS}

This work was supported by Ricerca Finalizzata 2009 and 2011 grants to PR-Q and AAM (RF-2009-1530290 and RF-2011-02352291) by the Italian Ministry of University and Research (No. 20108YB5W3-002 to AAM) and the European Research Council (to A. Mantovani).

\section{DISCLOSURE}

The authors declare that they have no competing interests as defined by Molecular Medicine or other interests that might be perceived to influence the results and discussion reported in this paper.

\section{REFERENCES}

1. Bottazzi B, Doni A, Garlanda C, Mantovani A. (2009) An integrated view of humoral innate immunity: pentraxins as a paradigm. Annu. Rev. Immunol. 28:157-83.

2. Bottazzi B, Garlanda C, Salvatori G, Jeannin P, Manfredi A, Mantovani A. (2006) Pentraxins as a key component of innate immunity. Curr. Opin. Immunol. 18:10-15.

3. Jaillon S, Jeannin P, Hamon Y, et al. (2009) Endogenous PTX3 translocates at the membrane of late apoptotic human neutrophils and is 
involved in their engulfment by macrophages. Cell Death Differ. 16:465-74.

4. Camozzi M, Rusnati M, Bugatti A, et al. (2006) Identification of an antiangiogenic FGF2-binding site in the $\mathrm{N}$ terminus of the soluble pattern recognition receptor PTX3. J. Biol. Chem. 281:22605-613.

5. Deban L, Russo RC, Sironi M, et al. (2010) Regulation of leukocyte recruitment by the long pentraxin PTX3. Nat. Immunol. 11:328-34.

6. Manfredi AA, Rovere-Querini P, Bottazzi B, Garlanda C, Mantovani A. (2008) Pentraxins, humoral innate immunity and tissue injury. Curr. Opin. Immunol. 20:538-44.

7. Salustri A, Garlanda C, Hirsch E, et al. (2004) PTX3 plays a key role in the organization of the cumulus oophorus extracellular matrix and in in vivo fertilization. Development. 131:1577-86.

8. Garlanda C, Bottazzi B, Bastone A, Mantovani A. (2005) Pentraxins at the crossroads between innate immunity, inflammation, matrix deposition, and female fertility. Annu. Rev. Immunol. 23:337-6.

9. Salio M, Chimenti S, De Angelis N, et al. (2008) Cardioprotective function of the long pentraxin PTX3 in acute myocardial infarction. Circulation. 117:1055-64.

10. Maugeri N, Rovere-Querini $P$, Slavich $M$, et al. (2011) Early and transient release of leukocyte pentraxin 3 during acute myocardial infarction. J. Immunol. 187:970-79 (2011).

11. Lech M, Rommele C, Grobmayr R, et al. (2013) Endogenous and exogenous pentraxin-3 limits postischemic acute and chronic kidney injury. Kidney Int. 83:647-61.

12. Souza DG, Amaral FA, Fagundes CT, et al. (2009) The long pentraxin PTX3 is crucial for tissue inflammation after intestinal ischemia and reperfusion in mice. Am. J. Pathol. 174:1309-18.

13. Rodriguez-Grande B, Swana M, Nguyen L, et al. (2013) The acute-phase protein PTX3 is an essential mediator of glial scar formation and resolution of brain edema after ischemic injury. J. Cereb. Blood Flow Metab. 34:480-88.

14. Norata GD, Garlanda C, Catapano AL. (2010) The long pentraxin PTX3: a modulator of the immunoinflammatory response in atherosclerosis and cardiovascular diseases. Trends Cardiovasc. Med. 20:35-40.

15. Tombetti E, Di Chio MC, Sartorelli S, et al. (2014) Systemic pentraxin-3 levels reflect vascular enhancement and progression in Takayasu arteritis. Arthritis Res Ther. 16:479.

16. Rovere P, Peri G, Fazzini F, et al. (2000) The long pentraxin PTX3 binds to apoptotic cells and regulates their clearance by antigen-presenting dendritic cells. Blood. 96:4300-06.

17. Zhu H, Cui D, Liu K, Wang L, Huang L, Li J. (2013) Long pentraxin PTX3 attenuates ischemia reperfusion injury in a cardiac transplantation model. Transpl. Int. 27:87-95.

18. Doni A, Musso T, Morone D, et al. (2015) An acidic microenvironment sets the humoral pattern recognition molecule PTX3 in a tissue repair mode. J. Exp. Med. 212:905-25.
19. Bosurgi L, Brunelli S, Rigamonti E, et al. (2015) Vessel-associated myogenic precursors control macrophage activation and clearance of apoptotic cells. Clin. Exp. Immunol. 179:62-67.

20. Poon IK, Lucas CD, Rossi AG, Ravichandran KS. (2014) Apoptotic cell clearance: basic biology and therapeutic potential. Nat. Rev. Immunol. 14:166-80.

21. Roumenina LT, Ruseva MM, Zlatarova A, et al. (2006) Interaction of C1q with IgG1, C-reactive protein and pentraxin 3: mutational studies using recombinant globular head modules of human C1q A, B, and C chains. Biochemistry. 45:4093-4104

22. Nauta AJ, Daha MR, van Kooten C, Roos A. (2003) Recognition and clearance of apoptotic cells: a role for complement and pentraxins. Trends Immunol. 24:148-54.

23. Ma YJ, Doni A, Romani L, et al. (2013) Ficolin-1-PTX3 complex formation promotes clearance of altered self-cells and modulates IL-8 production. J. Immunol. 191:1324-33.

24. Lech M, Rommele C, Kulkarni OP, et al. (2011) Lack of the long pentraxin PTX3 promotes autoimmune lung disease but not glomerulonephritis in murine systemic lupus erythematosus. PLoS One. 6:e20118.

25. Casciola-Rosen L, Nagaraju K, Plotz P, et al. (2005) Enhanced autoantigen expression in regenerating muscle cells in idiopathic inflammatory myopathy. J. Exp. Med. 201:591-601.

26. Rosen A, Casciola-Rosen L. (1999) Autoantigens as substrates for apoptotic proteases: implications for the pathogenesis of systemic autoimmune disease. Cell Death Differ. 6:6-12.

27. Sciorati C, Monno A, Ascherman DP, Seletti E, Manfredi AA, Rovere-Querini P. (2015) Required role of apoptotic myogenic precursors and tolllike receptor stimulation for the establishment of autoimmune myositis in experimental murine models. Arthritis Rheumatol. 67:809-22.

28. Introna M, Alles VV, Castellano M, et al. (1996) Cloning of mouse ptx3, a new member of the pentraxin gene family expressed at extrahepatic sites. Blood. 87:1862-72.

29. Shen W, Li Y, Zhu J, Schwendener R, Huard J. (2008) Interaction between macrophages, TGF-beta1, and the COX-2 pathway during the inflammatory phase of skeletal muscle healing after injury. J. Cell Physiol. 214:405-12.

30. Zammit PS, Partridge TA, Yablonka-Reuveni Z. (2006) The skeletal muscle satellite cell: the stem cell that came in from the cold. J. Histochem. Cytochem. 54:1177-11.

31. Brunelli S, Rovere-Querini P. (2008) The immune system and the repair of skeletal muscle. Pharmacol. Res. 58:117-21.

32. Garlanda C, Hirsch E, Bozza S, et al. (2002) Non-redundant role of the long pentraxin PTX3 in anti-fungal innate immune response. Nature. 420:182-86

33. Rigamonti E, Touvier T, Clementi E, Manfredi AA, Brunelli S, Rovere-Querini P. (2013) Requirement of inducible nitric oxide synthase for skeletal muscle regeneration after acute damage. J. Immunol. 190:1767-77.

34. Castiglioni A, Corna G, Rigamonti E, et al. (2015) FOXP3+ T Cells Recruited to Sites of Sterile Skeletal Muscle Injury Regulate the Fate of Satellite Cells and Guide Effective Tissue Regeneration. PLoS One. 10:e0128094.

35. Campana L, Santarella F, Esposito A, et al. (2014) Leukocyte HMGB1 is required for vessel remodeling in regenerating muscles. J. Immunol. 192:5257-64.

36. Capobianco A, Monno A, Cottone L, et al. (2011) Proangiogenic Tie2(+) macrophages infiltrate human and murine endometriotic lesions and dictate their growth in a mouse model of the disease. Am. J. Pathol. 179:2651-59.

37. Bacci M, Capobianco A, Monno A, et al. (2009) Macrophages are alternatively activated in patients with endometriosis and required for growth and vascularization of lesions in a mouse model of disease. Am. J. Pathol. 175:547-56.

38. Chazaud B, Mouchiroud G. (2014) Inflammaging: STAT3 signaling pushes muscle stem cells off balance. Cell Stem Cell. 15:401-02.

39. Schiaffino S, Pereira MG, Ciciliot S, Rovere-Querini P. (2016) Regulatory T cells and skeletal muscle regeneration. FEBS $\mathrm{J}$.

40. Relaix F, Zammit PS. (2012) Satellite cells are essential for skeletal muscle regeneration: the cell on the edge returns centre stage. Development. 139:2845-56.

41. Rayavarapu S, Coley W, Nagaraju K. (2011) An update on pathogenic mechanisms of inflammatory myopathies. Curr. Opin. Rheumatol. 23:579-84.

42. Casciola-Rosen LA, Anhalt G, Rosen A. (1994) Autoantigens targeted in systemic lupus erythematosus are clustered in two populations of surface structures on apoptotic keratinocytes. J. Exp. Med. 179:1317-30.

43. Han CZ, Ravichandran KS. (2011) Metabolic connections during apoptotic cell engulfment. Cell. 147:1442-45.

44. Summan M, Warren GL, Mercer RR, et al. (2006) Macrophages and skeletal muscle regeneration: a clodronate-containing liposome depletion study. Am. J. Physiol. Regul. Integr. Comp. Physiol. 290:R1488-95.

45. Tidball JG, Villalta SA. (2010) Regulatory interactions between muscle and the immune system during muscle regeneration. Am. J. Physiol. Regul. Integr. Comp. Physiol. 298:R1173-87.

46. Arnold L, Henry A, Poron F, et al. (2007) Inflammatory monocytes recruited after skeletal muscle injury switch into antiinflammatory macrophages to support myogenesis. J. Exp. Med. 204:1057-69.

47. Saclier M, Yacoub-Youssef H, Mackey AL, et al. (2013) Differentially activated macrophages orchestrate myogenic precursor cell fate during human skeletal muscle regeneration. Stem Cells. 31:384-96.

48. Mounier R, Theret M, Arnold L, et al. (2013) AMPKalpha1 regulates macrophage skewing at the 
PTX3 GUIDES MUSCLE DEBRIS CLEARANCE AND REPAIR

time of resolution of inflammation during skeletal muscle regeneration. Cell Metab. 18:251-64.

49. Sciorati C, Clementi E, Manfredi AA,

Rovere-Querini P. (2015) Fat deposition and accumulation in the damaged and inflamed skeletal muscle: cellular and molecular players. Cell Mol. Life Sci. 72:2135-56.

50. Sicari BM, Dziki JL, Siu BF, Medberry CJ, Dearth CL, Badylak SF. (2014) The promotion of a constructive macrophage phenotype by solubilized extracellular matrix. Biomaterials. 35:8605-12.

51. Locati M, Mantovani A, Sica A. (2013) Macrophage activation and polarization as an adaptive component of innate immunity. Adv. Immunol. 120:163-84.

52. Pucci S, Fisco T, Zonetti MJ, Bonanno E, Mazzarelli P, Mauriello A. (2014) PTX3: a modulator of human coronary plaque vulnerability acting by macrophages type 2. Int. J. Cardiol. 176:710-17.

53. Joe AW, Yi L, Natarajan A, et al. (2010) Muscle injury activates resident fibro/adipogenic progenitors that facilitate myogenesis. Nat. Cell Biol. 12:153-63.

Cite this article as: Vezzoli M, et al. (2016) Clearance of cell remnants and regeneration of injured muscle depend on soluble pattern recognition receptor PTX3. Mol. Med. 22:809-20. 